УДК 378.4

\title{
ФОРМИРОВАНИЕ МЕТАКОМПЕТЕНЦИЙ В ПРОЦЕССЕ ПРЕПОДАВАНИЯ ПЕДАГОГИЧЕСКИХ ДИСЦИПЛИН В УНИВЕРСИТЕТЕ
}

\author{
Лапицкий Олег Иванович \\ к.П.н., доцент \\ ФГБОУ ВО Благовещенский государственный \\ педагогический университет
}

\begin{abstract}
Аннотация: В статье рассматриваются значение компетентностноориентированных заданий по педагогике для формирования метакомпетенций будущего педагога, основанных на формировании деятельностных способностей. Рассматриваются некоторые подходы к оценке формируемых компетенций, в том числе через авторскую педагогическую технологию «Педагогическое стимулирование творческого саморазвития личности студента педагогического вуза».

Ключевые слова: компетентностный подход, компетентностноориентированные задания, метакомпетенции, оценка сформированности компетенций.
\end{abstract}

\section{THE FORMATION OF META-COMPETENCES ARE INFLUENCED IN THE PROCESS TEACHING PEDAGOGICAL SUBJECTS AT THE UNIVERSITY}

\section{Lapitsky Oleg Ivanovich}

\begin{abstract}
The article discusses the importance of competence-oriented tasks in pedagogy for the formation of metacompetencies of the future teacher, based on the formation of activity abilities. Some approaches to the assessment of the formed competencies are considered, including through the author's pedagogical technology «Pedagogical stimulation of creative self-development of a student of a pedagogical University».
\end{abstract}

Key words: competence-based approach, competence-oriented tasks, metacompetencies, assessment of competence formation. 
Профессиональная подготовка современного учителя претерпевает существенные изменения. Они связаны с интеграцией качества фундаментального университетского образования, хорошей практической подготовки и способности выпускника эффективно действовать в динамично меняющемся мире. Компетентностный подход в высшем образовании ориентирует нас на новый результат в профессиональной подготовке будущего учителя. Этот результат не связан с шаблонными оценками: образованность, подготовленность, широкая эрудиция и всё больше коррелирует с понятиями «компетенция», «компетентность». В педагогическом словаре понятие «компетентность» - это способность специалиста применять знания для решения практических задач в соответствии с его компетенцией, т. е. кругом полномочий, профессиональных обязанностей, вопросов, в которых данный человек достаточно сведущ, располагая необходимой информацией и практическим опытом [1, с.17].

От выпускника сегодня требуется не столько умения воспроизводить полученные знания, сколько творчески подходить к решению профессиональных задач, быть способным к постоянному самообразованию, личностному и профессиональному самосовершенствованию. Педагогиисследователи В.И. Андреев, Е.В. Бондаревская, В.В. Сериков и другие рассматривают саморазвитие как основу обновления образования и важнейшую профессиональную компетенцию педагога, эффективную составляющую профессиональной деятельности. Эту компетенцию сегодня называют метакачествами специалиста, метакомпетенцией (от греческого «meta» - между, после, через; часть сложного слова, означающая следование за чем-либо, переход к чему-либо другому), в более узком значении - это умения учиться, овладение способами мыследеятельности. В общем среднем образовании метапредметная компетенция обучающегося формируется через овладение универсальными учебными действиями. Эти компетенции надпредметные и ключевые, формируются благодаря опыту творческой деятельности, эффективного решения задач в нестандартных ситуациях, опыта осуществления эмоциональноценностных отношений.

В зарубежных подходах метакомпетенции относятся к группе «мягких» навыков (от англ. soft skills), которые повышают эффективность решения профессиональных задач. И здесь высоко ценятся умения 
работать в команде, управлять собственной карьерой, прогнозировать профессиональные перспективы, способности к межличностному взаимодействию и принятию нестандартных решений и др. [2].

В отечественном профессиональном образовании эти компетенции можно отнести к группе универсальных, которые существенно влияют на реализацию всех профессиональных задач. Это своеобразный ресурс дальнейшего самообразования и самоорганизации успешной жизнедеятельности.

Для решения задач формирования метапредметных педагогических компетенций занятия по педагогике призваны выполнить важнейшую роль. Обычно разрабатываются компетентностно-ориентированные задания под группу компетенций: универсальных, общепрофессиональных и более узких профессиональных. Эти задания могут быть оценочными средствами в рабочей программе. И если раньше нормированной оценке подвергались только тесты, то сейчас спектр оценочных средств достаточно широкий: творческие задания, деловые игры, кейс-задачи, эссе и т.п. И по всему этому спектру оценочных средств разрабатываются нормы оценки. Конечно, в количественных показателях можно осуществлять внутривузовский мониторинг качества достижения сформированных компетенций, он сегодня неплохо отслеживается в системе электронного обучения университета.

Сложнее всего оценить сформированность тех самых умений учиться, метакомпетенций. Наши исследования в данной области показывают, что метакомпетенции влияют на качество образовательного результата. А качество это не только высоко оцененные тесты, а целый спектр педагогических умений, способностей, необходимых для подготовки современного учителя. Например, как можно оценить способность взаимодействовать с участниками образовательных отношений в рамках реализации образовательной программы (ОПК-7), или способность организовать совместную и индивидуальную воспитательную деятельность обучающихся в соответствии с требованиями ФГОС (ОПК-3). С помощью только тестов эти способности невозможно проверить, нужны задания, где студент может осуществить пробу сил, провести рефлексию и ответить, что не получилось и почему.

Всё-таки ядром педагогических компетенций, как утверждает Э.Ф. Зеер, становятся деятельностные способности, как совокупность способов 
действий в заданных педагогических условиях или в условиях неопределённости, без которых планируемые компетенции не могут быть сформированы [3].

На учебном занятии реализуется важная часть непрерывного процесса личностно-профессионального саморазвития будущего учителя, где он входит в контекст современной культуры вместе с преподавателем, который призван стимулировать, актуализировать и поддерживать личностный рост, помогать утверждать образ собственного «Я» не как данности, а как «регулятивной идеи». Для запуска механизмов саморазвития вузовскому преподавателю необходим новый взгляд на личность обучающегося, как не только просвещаемой и познающей, но и как смысло- и целеполагающей, самосозидающей, преобразующей себя и жизнь. И нужен новый взгляд на образовательный процесс и учебное занятие как пространство творческого саморазвития личности.

Для апробации этих идей мною была разработана и внедрена авторская педагогическая технология «Педагогическое стимулирование творческого саморазвития личности студента педагогического вуза» [4]. Цель и задачи технологии: развитие потребности и способности к творческому саморазвитию личности студента педагогического вуза; формирование метапредметных компетенций, необходимых для педагогической профессии; повышение мотивации к изучению педагогических дисциплин в вузе.

Изменилось и целеполагание в организации учебных занятий. Варианты метапредметных целей учебного занятия: «Развивать навыки самоконтроля и самооценки для формирования внутреннего локуса контроля личности студентов», «Развивать навыки самоорганизации, самообразования при выполнении самостоятельной и исследовательской работы», «Воспитывать потребность в саморазвитии у студентов, поощрять стремление к самостоятельности, инициативе, творческому поиску решения педагогических задач», «Сформировать устойчивые навыки и умения педагогического моделирования и проектирования» и т.п. В этих формулировках новых целей учебных занятий прослеживается и суть понятия - педагогическая метакомпетенция.

Конечно, «прибавки» в личностном росте обучающихся появились не сразу. Этот процесс длительный, требуется минимум 2-3 года, чтобы доказать эффективность применяемой технологии. Но некоторые результаты мы зафиксировали сразу. Это изменение мотивации учения, изменение 
отношения студентов к изучаемому предмету, проявляющиеся в возросшем интересе, познавательной потребности, положительных отметках, возросшем уровне самостоятельности и самоорганизации, рефлексивных навыках самопроверки и самоконтроля.

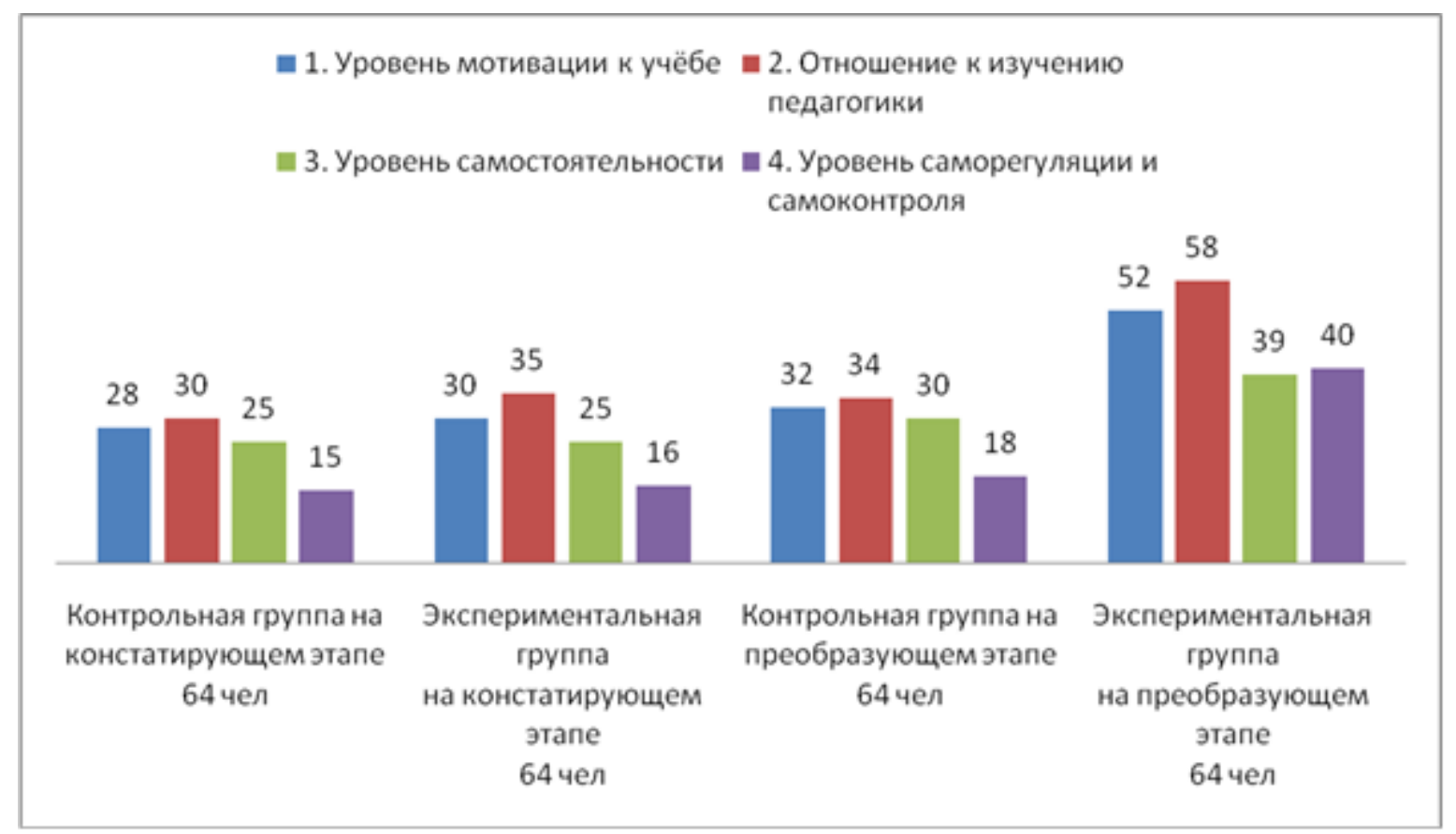

\section{Рис. 1. Динамика изменений основных показателей за 2 года работы по авторской технологии}

На рисунке 1 показана динамика изменений по показателю «высокий уровень» в абсолютном количестве обучающихся (без интерпретации в данной статье показателей среднего и низкого уровней) в контрольной и экспериментальной группах (по трём учебным группам в контрольной и экспериментальной, всего 128 чел первого и второго курсов). Изменения фиксировались с помощью стандартизированных методик изучения мотивации к учению, развития самостоятельности и уровня саморегуляции и самоконтроля (авторы О.И. Мотков, В.И. Андреев, А.М. Пригожин, Е.В. Эдман, а также анкет-опросников для изучения отношения к изучению педагогики, составленных нами). На диаграмме показаны результаты изменений в показателях высокого уровня по самооценке самих обучающихся. Для объективности исследования была также проведена внешняя оценка изменений в выделенных четырёх критериях, в которой участвовали преподаватели вуза, работающие в данных группах. Нами было выявлено, что и при внешней оценке преподавателей данные показатели в 
экспериментальных группах также выросли. Педагоги отмечали, что у большинства студентов в целом изменилось отношение к учёбе по многим предметам, они стали более ориентированными не только на результат, но и на процесс добывания знаний, активное участие в семинарских занятиях с проявлениями творческой активности, усилением механизмов рефлексивности самой учебно-познавательной деятельности, овладением многими навыками самостоятельного поиска, обработки и представления информации.

Следует заметить, что мы поставили в известность преподавателей об апробации данной технологии, её целях и задачах, и у самих преподавателей был интерес что-то попробовать, изменить. Уверен, что для качественной работы в данном направлении нужна именно слаженная работа всего педагогического коллектива. Поэтому нами были запланированы методические семинары для педагогов, знакомство с приёмами, методами работы, чтобы стимулировать интерес к самой технологии. Увлечение только приёмами и отдельными методами не даст желаемого нового качества образовательной деятельности, необходим целостный подход. У ряда преподавателей появился интерес к организации так называемых тьюториалов для студентов младших курсов, где они смогут развивать метакомпетенции, как умения учиться, и заложить у студентов потребность в непрерывном образовании.

В ходе апробации технологии нами было замечено, что по таким показателям, как уровень самостоятельности, саморегуляци и самоконтроля не было высоких приращений. Сами студенты в анкетах и в диагностических беседах отмечали, что, обучаясь в средних школах, они почти не учились таким навыкам: быстро находить информацию и предлагать способы решения проблем, структурировать, моделировать и презентатировать разными способами информацию, учиться делать самоанализ и самооценку сделанной работы. Локус педагогического контроля в средней школе был сфокусирован на внешней оценке, преобладании репродуктивных методов работы с информацией. Развитие важнейших свойства личности, связанных с развитием волевой саморегуляции, формированием устойчивых потребностей в саморазвитии, требуют особой педагогической инструментовки, которой владеют не в полной мере все педагоги. Не случайно главный вектор новых ФГОС направлен на развитие и укрепление 
«самости»у каждого обучающегося, их образовательную инициативность и самостоятельность, регулятивные универсальные учебные действия.

Раскроем некоторые аспекты авторского подхода. Технология базируется на сформулированных и обоснованных нами принципах: опережения, пробуждения потребности в саморазвитии, педагогической инверсии, резонанса и контекстности обучения.

Контекстное обучение (лат. contextus - тесная связь, сцепление, сплетение) - обучение, в котором «сцеплены» в единую модель предметный и социальный компоненты будущей профессии, тем самым создаются условия для осмысленного понимания процесса учения студента и становления его как будущего специалиста в избранной профессии (А.А. Вербицкий).

Согласно Вербицкому А.А. [5], овладение профессиональными компетенциями осуществляется в иных условиях, посредством трёх взаимообусловленных моделей: семиотической, имитационной и социальной. Основные дидактические компоненты в образовательном процессе вуза проблемная ситуация, проектирование профессиональных задач и деятельность (у Вербицкого - поступок как единица деятельности), реализуемые в контекстном сцеплении учебной, квазипрофессиональной и учебно-профессиональной деятельности.

Если мы хотим получить не просто физика, химика, историка, а учителей физики, химии, истории, то необходимо в педагогическом процессе вуза на всех уровнях образовательного контекста (учебном, квазипрофессиональном, учебно-профессиональном) задавать лучшие образцы педагогического взаимодействия, постоянно проектировать ситуации погружения в педагогическую профессию. Любое учебное занятие - это педагогический тренинг, на котором студент, будущий педагог, учится владеть аудиторией, своей мимикой, голосом, жестами, принимать решения, ставить задачи.

Для профессионально-творческого саморазвития важно постоянное осмысление и рефлексия, что происходит с моим личностным «Я»и моим профессиональным «Я», что необходимо ещё успеть сделать, чтобы приблизиться к современному образу учителя. Выход к своему «Я» может реализовываться через индивидуальное отношение к учебной задаче как задаче на открытие, понимание себя («мы не только познаем мир педагогики, но и открываем себя как человека»; осознание своих интересов в мире 
изучаемой науки, к личностям выдающихся ученых, к теории, к эксперименту, к смежным областям человеческой культуры).

Создавать разнообразные, отвечающие индивидуальным склонностям обучающихся учебные ситуации и роли, ставить «задачи в лоб» - найти свое место в изучаемой науке. Или, например, рассмотрение таких проблемных ситуаций: «Насколько готово человечество решать сегодня экологические проблемы и достаточно ли ваших способностей, знаний, стремлений, чтобы решать эти проблемы?».

Поддерживать у студентов стремление знать себя, свои психофизиологические особенности: реакции, функции, влечения, способности, темперамент, а на этой основе особенности характера, стиля и тактики собственной жизни. Это можно осуществлять через оценку своих учебных перспектив, возможностей (планирование достижений и продвижений) и самооценку результатов, но не в пятибалльной шкале, а как качественный самоанализ.

Образ современного учителя у наших студентов зачастую сформирован под влиянием школьных педагогов, у которых они учились. Этот образ может быть как позитивным, так и негативным. Так, 28\% студентов первого курса двух исследуемых факультетов БГПУ ответили, что выбор педагогической профессии был обусловлен влиянием школьного учителя, $25 \%$ в силу семейных традиций, 33\% отдали предпочтение из-за авторитета вуза и хороших отзывов бывших студентов, остальные - случайно попали в университет. Всё-таки половина студентов приходят к нам внутренне мотивированных на педагогическую профессию [6].

На учебных занятиях по педагогике и психологии мы формируем у будущих учителей некий новый образ учителя, близкий к идеальному. Так, в компетентностно-ориентированном задании деловой игре «Образ современного учителя» студентам необходимо было выделить пять наиболее необходимых качеств, обеспечивающих успешность в профессии учителя и оценить его по шкале от -3 до +3 . Обращает на себя внимание то, что относительно высоко оценили студенты такие качества, как высокая культура и интеллигентность, личная скромность и сдержанность, культура отношений, терпимость к недостаткам в ряду с другими качествами: справедливостью, выраженной гражданской позицией, эрудицией, мастерством преподавания своего предмета, преданностью педагогической профессии, целеустремлённостью, принципиальностью и честностью, 
порядочностью и ответственностью, бескорыстностью и щедростью, умением урегулировать конфликты.

Формируя образ современного учителя, мы пришли со студентами к выводу, что самотворение педагога в себе интеллигентной, саморазвивающейся личности невозможно без осмысления ценностей педагогических (профессиональных) и личных. И если учитель интеллигентная личность, с высокой потребностью в саморазвитии, он сам творит и пишет свою судьбу, находя для себя источники самодвижения [6].

Личность будущего учителя следует рассматривать как личность, способную быть духовной, индивидуальной, т.е. способную воспринимать и развивать мировую и национальную общую и педагогическую культуру. Такая личность имеет высокую потребность в творческом саморазвитии, рефлексии, красоте, продуктивном общении. Плохим топливом для саморазвития будут упрёки педагогов: «как ты попал сюда, трёх слов связать не можешь», «какой из тебя будущий учитель, если ты безответственный» и т.п. Контекстный принцип обучения побуждает вузовского преподавателя постоянно задумываться о том, что его стиль общения, отношение к своему труду могут стать некоторой матрицей для будущей профессиональной деятельности его учеников, катализатором саморазвития или очень «плохим топливом» для дальнейшего самопреобразования.

На занятиях по педагогике мы используем различные компетентностно-ориентированные задания для пробуждения творческого саморазвития будущих учителей. Например, разработать нестандартные формы оценивания учащихся, не ущемляя их прав, придумать несколько приёмов привлечения внимания детей при изучении трудной темы, разработать вариативные способы предъявления требований к ученику, постоянно нарушающему дисциплину.

Большое внимание уделяется заданиям по педагогическому моделированию, где разрабатываются авторские модели школы будущего, социально-педагогических комплексов поддержки детей, попавших трудную жизненную ситуацию и др. Различные деловые игры и кейс-ситуации позволяют решать задачи формирования компетенций по развитию способностей взаимодействовать с участниками образовательных отношений.

Написание педагогических эссе после просмотра фильмов на педагогическую тематику («Это мы не проходили», «Расписание на 
послезавтра», «Училка», «Класс коррекции» и др.) позволяет оценить степень сформированности важных педагогических компетенций: умение видеть, вычленять и формулировать педагогические проблемы и предлагать способы их решения. Если говорить об оценке таких заданий, то некоторые из них входят в оценочные средства рабочей программы по педагогике, многие видеокейсы и фильмы обсуждаются непосредственно на занятии в форме перекрёстных дискуссий, дебатов или педагогической рефлексии.

Наш опыт проектирования и внедрения компетентностноориентированных заданий в процессе преподавания педагогики позволяет уверенно утверждать, что такой подход способствует формированию нового качества педагогического образования. И это качество выражается в росте мотивации к педагогической профессии, овладении метаспособностями (приёмами самоорганизации, самообразования, самопроектирования, внутреннего локуса контроля), проявлении творческой самореализации в различных видах учебной и внеучебной деятельности.

В знаниево-ориентированном подходе профессионального образования доминирующим был аспект передачи знаний, опыта почти в готовом виде, натренированности памяти обучающегося на запоминание и воспроизведение больших массивов информации. Безусловно, знания являются отражением социального опыта человечества, способствуют успешному вхождению человека в социум. Сегодня знания - не только сила, но и средство решения профессиональных и жизненных задач. Содержательная и структурная ориентация педагогического образования на формирование компетенций (ФГОС ВО) и трудовых умений и знаний (профессиональные стандарты) предполагают необходимость изменений не только в организации образовательного процесса обучения, но и в технологиях обучения, подходах к оценке формируемых компетенций.

\section{Список литературы}

1. Педагогический энциклопедический словарь/ гл. ред. Б.М. Бим-Бад. - М.: Научное изд-во «Большая российская энциклопедия», 2002. - 528 с.

2. Heckman J. J., Kauts T. Hard evidence on soft skills // Labour Economics. 2012. Vol. 19. Iss. 4. P. 451-464

3. Зеер, Э. Ф. Компетентностный подход как методологическая позиция обновления профессионального образования / Э. Ф. Зеер // Вестник Учебно-методического объединения по профессионально-педагогическому 
образованию / Рос. гос. проф.-пед. ун-т. - Екатеринбург, 2005. - Вып. 1 (37). - C. 5-12.

4. Технологии профессионально-ориентированного образования: учебно-методическое пособие /автор О.И. Лапицкий. - Благовещенск: Изд-во БГПУ, 2018. - 138 с.

5. Вербицкий А. А. Теория контекстного образования как концептуальная основа реализации компетентностного подхода //Коллекция гуманитарных исследований. - 2016. - № 2(2). - С. 6-12.

6. Лапицкий О.И. Я б в учителя пошёл, пусть меня научат...//Народное образование. - 2015. - №10. - С.72-78.

() О.И. Лапицкий, 2020 